\title{
The Footprint of Walking and Street Activities to the Architecture of the Street: The Case of Dar es Salaam
}

\author{
Fortunatus Bahendwa, Henry Rimisho, Angelica Katama \\ School of Architecture, Construction Economics and Management, Ardhi University, Dar es Salaam, Tanzania \\ Email: fortub72@gmail.com, henryrimisho@yahoo.co.uk,nkatama@gmail.com
}

How to cite this paper: Bahendwa, F., Rimisho, H., \& Katama, A. (2019). The Footprint of Walking and Street Activities to the Architecture of the Street: The Case of Dar es Salaam. Current Urban Studies, 7, 321-340.

https://doi.org/10.4236/cus.2019.73016

Received: June 11, 2019

Accepted: September 2, 2019

Published: September 5, 2019

Copyright $\odot 2019$ by author(s) and Scientific Research Publishing Inc. This work is licensed under the Creative Commons Attribution International License (CC BY 4.0).

http://creativecommons.org/licenses/by/4.0/

\begin{abstract}
Street and the activities bound within it associate the social, cultural, economic and spatial significance with walking, apart from its mobility aspect of moving from point $\mathrm{A}$ to $\mathrm{B}$. The conventional requirement for street design provides for distinctive and defined spatial organization, visual expression and functions. Given to socio-economic condition of the population in cities of least developed countries, street has become part of platform for both walking and economic activities. In this respect, the streets are exposed to transforming formal and informal socio-economic activities amidst the hardly isolated function of walking. Such street dynamics have influenced the street organization and hence the architecture of the street questioning the authenticity of conventional design orthodox. The case study is done in Dar es Salaam city to acquire empirical data that provide insight on such phenomenon. It is revealed that the influence of socio-economic activities in streets overrules the conventional requirements such that they shape the walking condition and the architecture of the street. Thus, it is concluded that the design for walking has to take into consideration the socio-economic context of the locality and its impact to the architecture of the street in order to achieve convenience of both walking and the street visual expression.
\end{abstract}

\section{Keywords}

Walking, Street Architecture, Socio-Economic Activities, Spatial Design

\section{Introduction}

Walking is still a crucial means of mobility in cities of developing countries where the majority of residents constitute the low income cadre. Walking con- 
stitute cheap and affordable means of mobility creating opportunity for useful urban street for walking people and public space which entertain socio-economic activities dominated by street formal and informal trading alongside walking. Such spatial settings contravene the legal and conventional design conditions which require strict separation of urban activities and provision of defined street architecture. The walking activity and other street dynamics create spatial condition which requires professional explanations in order to contribute new insight in street design.

Walking needs less sophisticated infrastructure and an important link to other modes of mobility since all means of transport start and end with walking (Blaga, 2013; WHO, 2011). While walking connects people with urban space, activities and hence influences space quality, street pattern, status of enclosure and configuration. In addition, cities are best experienced by walking people at street level who engage in various urban activities. In this respect urban space cannot be thought of without adequately considering the streets, urban activities and walking people which make the urban space and street an important subject of study (Blaga, 2013; Alfonzo, 2005; Transport for London, 2004). The use of urban space and the street reflect social, economic and cultural factors within the local context implying the importance to analyse the link of walking and the urban activities to street architecture. Furthermore, walking and urban activities are linked with environmental, health, economic, investment and design issues which are directly associated with physical urban space and the architecture of the street (Reyer, Fina, Siedentop, \& Schlicht, 2014; Planning Institute Australia, 2003; National Association of City Transportation Officials, 2013; Wundelich, 2008; Reyer, Fina, Siedentop, \& Schlicht, 2014). Such broader perspective of sustainable consideration in city design discourses has to address the improved design efficiency of urban street.

The concept of the street, walking and its architectural significance

A street as a thread, path or road bound by buildings provides communication, interaction and movement of people, goods and services while it shelters the outdoor activities. Streets are dynamic spaces that adapt change over time to support environmental sustainability, public health, economic activity and cultural significance. Urban street plays an important role in affecting the microclimate of the street and hence the city at large (Shishegar, 2013; Bourbia \& Fouzia, 2010). It is also the platform where walking dominates the means of communication, interaction and other activities. It represent the common attributes of the users and facilitates communication and interaction between people and groups and thus serve to bind together the social order of the local urban community (Shortell, 2016; Ramsden, 2014; Wallmann, Bucksch, \& Froboese, 2011; Wineman, Kabo, \& Davis, 2009; Hamilton-Baillie, 2008; Moughtin, 2003; Ben-Joseph, 1995).

The design of street is associated with walking convenience, connecting the integrity of local community and the strangers from other parts of the city 
(Cubukcu, 2013; Alfonzo, Boarnet, Day, Mcmillan, \& Anderson, 2008; Jacobs, 1961). Thus, the street elements and features which enhance human scale and proportions are encouraged since it provides convenient opportunity for waking, standing, sitting, recreating, experiencing the space, avoiding unintended view, facilitating architectural detailing and improving the sense of place (Wundelich, 2008; Levy, 2006; Moughtin, 2003). The street have the component of serving the users' everyday requirements which stand as the basis of street function and activities, physical configuration, quality of space and hence the architecture of space (Kärrholm, Johansson, Lindelöw, \& Ferreira, 2014; Reyer, Fina, Siedentop, \& Schlicht, 2014; Blaga, 2013). The street professional variables and the prospects to achieve them depend on the active influence in control of urban space by the formal or informal regimes, especially in the cities of least developed countries. In a nutshell, the role of professional design approach to develop architectural outcome may be affected by the dynamic nature of both outdoor and indoor activities on street, creating the need for further study of unpredictable nature of the street.

There is more recognition in design professional perspective that the features of street architecture are not static due to evolutionary nature of the street (Hamilton-Baillie, 2008; Moughtin, 2003). This result from the common urban processes where contestation for space use and exploitation of its value lead to space dynamics by which space and time determine the direction of the architecture and pattern of the street. The transformation of the street involves a variety of actors such as property owners, business owners, street users, professionals and policymakers. The combination of socio-economic forces, cultural effects and the complex interaction of various actors in competition to extract the space value affect the function and physical configuration of space. In case of cities in less developed countries, the contestation of formal and informal processes may add to the dynamics of the street with the effect in terms of quality, space experience, enjoyment and sense of place.

The street quality is further associated with factors such as safety, comfort, connectivity, reliability and pleasurability which affect walkability, aesthetic value, functional requirements, the market forces, socio-cultural dimension and others (Vestergaard, Olesen, \& Helmer, 2014; National Association of City Transportation Officials, 2013; Makki, Surat, Che-Ani, Farkisch, \& Mokhtarian, 2012; Mehta, 2008; Alfonzo, Boarnet, Day, Mcmillan, \& Anderson, 2008). Koohsari et al. (2013) note that parameters such as physical urban environment, users' self-preferences and design aspects affect the connection among walking people, urban activities and the enclosing spatial character in supplementing each other. While the contribution of professional designers in effecting the architecture of the street could not be ignored, the influence of other actors who are directly associated with everyday processes of the street have a key influential role on the function and physical configuration of the streets which need to be assessed (Temelová \& Novák, 2011). In this regard, walking as communicable, 
interactive and mobility component in the street need to be analysed on its contribution on organization and physical configuration of the street and hence the architecture of the street.

\section{Methodology}

The literature search is done to present the relevant concepts, theories and perspectives on urban street activities including walking, the socio-economic activities, urban space and their effect to urban design. From the fact that the study is space specific, the case study method is adopted where Dar es Salaam city is selected. The case is selected based on its information richness on the intensity of street walking, concentration of street socio-economic activities and variety of space characters. Further, sample urban spaces, urban activities and urban routes are selected for data collection. Major components studied are walking connectivity, major destinations, quality of walking facilities, walking experience in urban space, major space uses (urban activities), major public spaces, formal and informal space uses and formal and informal walking provision. The main methods applied include observations, mapping of specific urban streets and spaces, studying street activities and spaces, document analysis, interviewing walkers, petty traders and city officials and consulting key informants. Analysis is done through coding, classification, categorizing and tabulating reducing the empirical data into legible evidence sufficient to draw conclusions based on research questions. Descriptive, illustrations and simple statistical charts are used to present analysed data.

\section{Choice of case study areas}

Dar es Salaam is the major city in Tanzania, highly populated, commanding social, economic and cultural diversity which influence massive city development and enormous urban activities. Such characters make Dar es Salaam city to influence major social and economic activities which involve exclusive occupation of urban public spaces which include sizable walking population. Dar es Salaam city is the area where the researchers reside, thus they have participatory feel, the background knowledge and the ease of access. City centre as core area where concentration of commercial activities takes place and attract immense movements including walking are chosen as sub-cases to be convenient study areas. Routes which command certain level of activities including petty trading and walking were randomly chosen, as further sub-cases in the city.

\section{Interviews and observations}

Structured questionnaires are used to generate the social perception on interaction of walking to street use and configuration based on socio-cultural aspects and the influence of informal city practices. The questionnaires seek the opinion of walkers and petty traders on spatial use, the interaction of different uses and architectural quality of the street. Methods such as observation, document analysis and map reading are utilised to supplement the interviews. Formal structure, city planning, design regime and the urban mobility system are studied to 
get the city explanation at local level. Key urban spaces and urban streets are selected to study walking characteristics, socio-economic activities including formal and informal practices, street use and configuration through map reading, observations and interviews. The aim is to find the niches by which walking, street activities and physical configuration integrate to create meaningful street architecture and contribute to street design and hence urban design discourse at large.

Issues associated with peoples' desire, feeling, behaviour, attitude and opinion, which cannot be acquired through observations, are sought through interviews. The target respondents are the walkers (pedestrians) and the petty traders who form the majority of activities taking place in urban streets. The urban planners, designers and managers at city authority level are interviewed on the walking status based on street design, urban design and planning respective city. In particular, the interview for walkers covers the walkers' preference of walking, the preferred mode of transport, urban places preferred, feeling of safety, comfort, satisfaction, sensuous effect to the space and the attitude towards informal activities in urban space. The petty traders are interviewed on the criteria of choice of locations, quality of space occupied, acquisition of customers and the effect of their presence to the walkers. In order to enhance reliability of response, based on studied average of 100 walkers passing on a given point of street per hour, at least 120 walkers and 60 petty traders are interviewed in Dar es Salaam. The distribution of respondents is 40 walkers and 20 petty traders along the selected less populated case study route forming Makunganya, Indira Gandhi and Aggrey streets in the city centre and 80 walkers and 40 petty traders along the highly populated case study route forming Nyamwezi and Tandamti Streets in Kariakoo. The interviews and observations done at sample streets in the city centre are meant to draw a clue on walking condition and the character of socio-economic activities in the street which can give a wider view of spatial condition to the architecture of the street. This provides the basis for making conclusions and general explanation concerning the individual street and the whole city.

\section{Result}

The presentation of results includes the findings regarding the observation outcomes on walking characteristics, the inventory of socio-economic activities, space use and quality. The reflection and perspectives from the walkers and petty traders on walking environment, the nature of street activities and street characteristics are also presented. Further, the discussion on the walking condition as well as street activities is done to uncover their significance to design and hence architecture.

\subsection{The General Aspects of Walking and Activities in Streets}

This part provides the observation results on the street content including the 
building, the walkways, the street furniture and vegetation. It also explains how the street condition affect the activities such as walking and trading based on the availability, condition and quality of walkways.

\section{Availability, continuity, Quality and Condition of walkways}

Most of streets in Dar es Salaam city centre are noted with walkways, which are dedicated for pedestrians but in some areas the construction sites hoardings, street vendors and the temporary car parking interfere the walkway continuity (see Figure 1).

In some few cases, the barriers to prevent car from parking are provided (see Figure 2). Walkways are finished with concrete paving of different pattern and colour while few are finished with asphalt materials. Some walkways are covered forming a part of the "arcades" within the buildings. In some cases the ground floor frontage is extended by providing the awning under which the walkways are accommodated. The continuity of walkways is mostly hampered by a number of obstructions as explained above. Figure 1 and Figure 2 present some of street characters mentioned above.

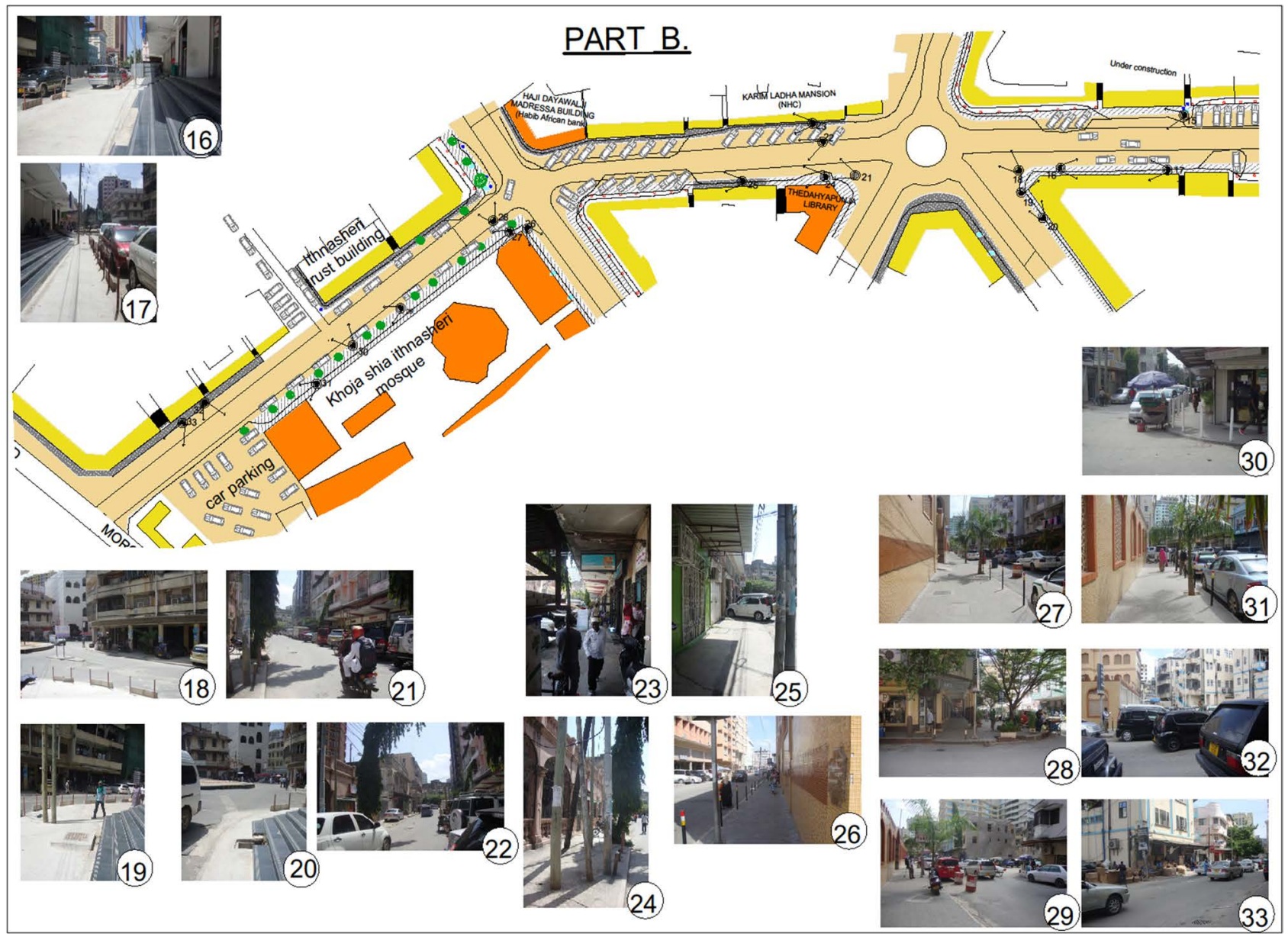

Source: Google Map and Authors' construction

Figure 1. Makunganya/Indira Ganthi Street with indicating walking condition on accessibility, continuity, obstacles, architectural environment, safety, comfort, pleasurability and street activities. 

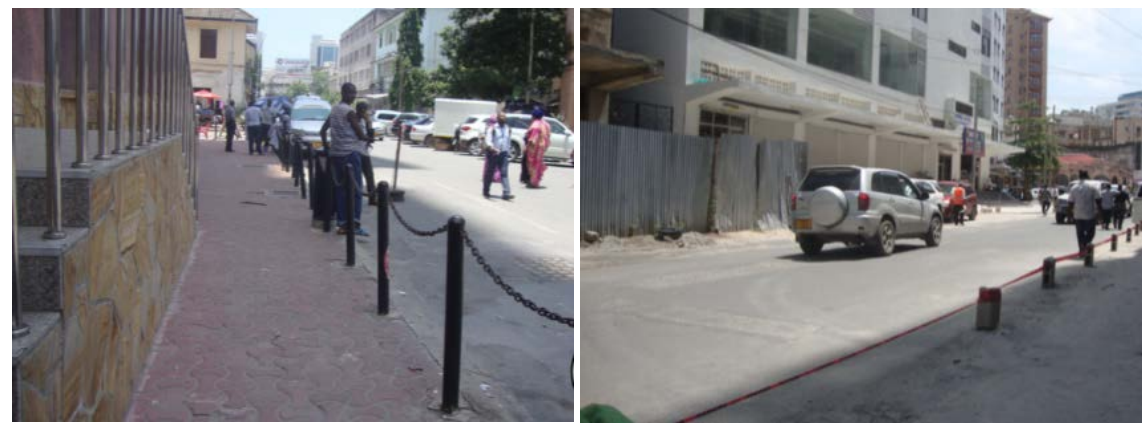

Source: Field photos

Figure 2. Left. Makunganya/Indira Ghandhi Street. This seems like a well demarcated walkway but, in practice, the barrier is provided to prevent pedestrian from moving close to the building. Walking people are thus pushed to the roadway meant for cars. Right. Construction site hoarding on a walkway pushing the walkers to the roadside.
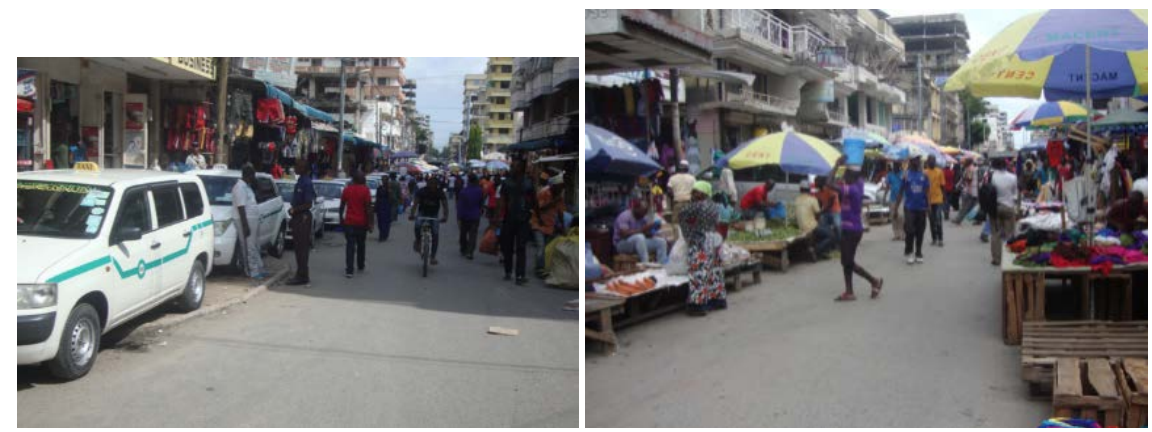

Source: Field photos

Figure 3. Nyamwezi Street in Kariakoo area. Petty trading activities, car parking and other socio-economic activities have taken over the traditional sidewalk for pedestrians and transformed some of streets into markets. Walking being pushed to the centre of the road, has assumed to take over the car domain.

In the streets of Kariakoo, the most populated urban space in Dar es Salaam, it is observed that walkways are available in most streets but they are dominated by other uses such as car parking, street vending and other social activities (see Figure 3). In this situation, people are forced to walk along the car carriage way. It was noted that some walkways were lacking routine maintenance. Sharp corners are also noted as the result of newly developed structures regardless of the intended curved corners, which would provide easy flow, respect to natural human movement, safe turning and continuity. Few streets had no walkways thus making pedestrians to use the same car carriage ways with motor vehicles and motorbikes.

\subsection{Social-Economic Activities and Walking Behaviour}

The street petty trading is the main street activities occupying most walking spaces. The activities range from arranging of goods on ground, creation of simple display tables or holders or producing makeshift structures to accommodate goods for sale which also enhance weather free business operations (see Figure 4). 


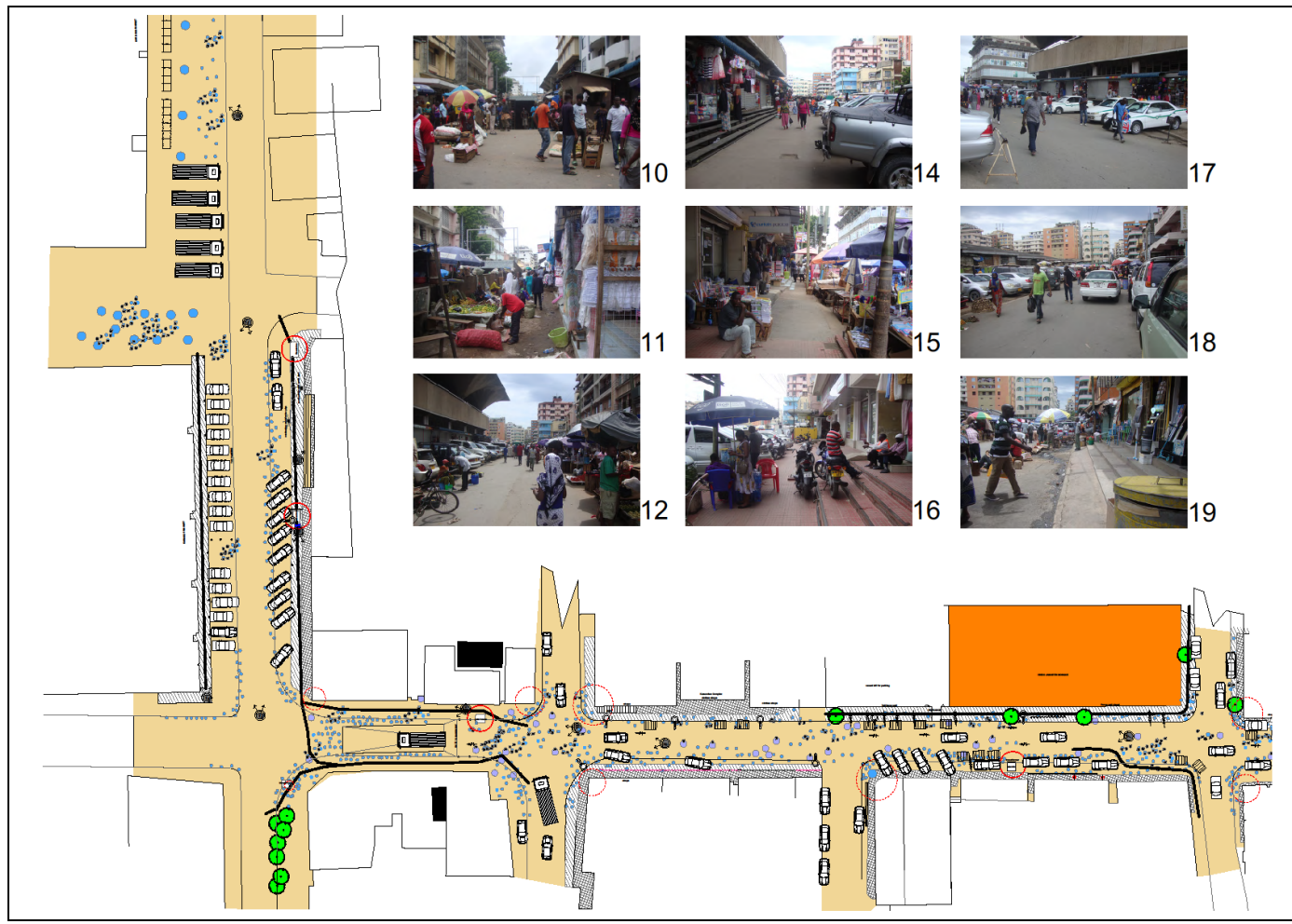

Source: Field photos and Authors' construction.

Figure 4. Nyamwezi/Tandamti streets housing highly intensive informal trading activities, walking, parking and other socio-economic activities creating new street pattern and specific visual impression.

Some legal businesses are also noticed to extend on walkways increasing on-street activities and interfering with walking continuity.

In Kariakoo, the dedicated walkways are occupied by other numerous informal trading activities which limit the walking space and make both the moving cars and the pedestrians to use the narrow remaining central part of the road. The occupation of street sides and the organization of selling merchandise in the open or in makeshift shelters create a variety of street image with visual character of its kind (see Figure 4). The whole scenario limits both the cars and pedestrians speed. The dense population in the street show the underlying relationship creating interaction of traders, customers, walkers, riders drivers and other actors. The combination of walkers and trading activities dominate the physical image of the street and hence the architecture. In this case, the street utilitarian aspects are dominant while the physical features taking lesser status.

\section{Special events which may affect street activities and walking}

It is noted that, in some streets in Dar es Salaam, there are some Friday Muslim worship services in mosques which extend to outdoor space leading to momentarily closure of street activities. With limited outdoor area, the street along the mosque is closed to allow the believers to worship outdoor and provide car parking for worshipers. Further, temporary trading points are set in place to serve the crowd of worshipers. Such temporary closure of street activities appear 
to be socially and culturally acceptable and thus not considered as interference to street activities. This is one of street dynamics contributed by the street activities acceptable to street users which momentarily change the pattern, organisation and the use of street (see Figure 5).

\subsection{Street Elements and the Walking}

Different elements together with building elevations aggregate to form a street and enclose activities within. Such elements as buildings, public facilities, street furniture and vegetation, comprise a great part of the street and they are great pulling factors to the street architecture.

Buildings in the city centre of Dar es Salaam along Indira Ghanthi street are mostly provided with walkways for pedestrian movement. However, some walkway are provided with barriers to restrict walking as if they are not for public uses (see Figure 6). Some investors on commercial buildings such as banks and hotels tend to assume full ownership of roadside spaces by blocking pedestrian passage ignoring the public status of urban building frontage. A few investors in some buildings have enhanced the walkways by providing the physical barrier to the cars parking and providing comfortable environment for walking by improving walking surface, provision of green plantation and limiting petty trading along the streets (see Figure 6).

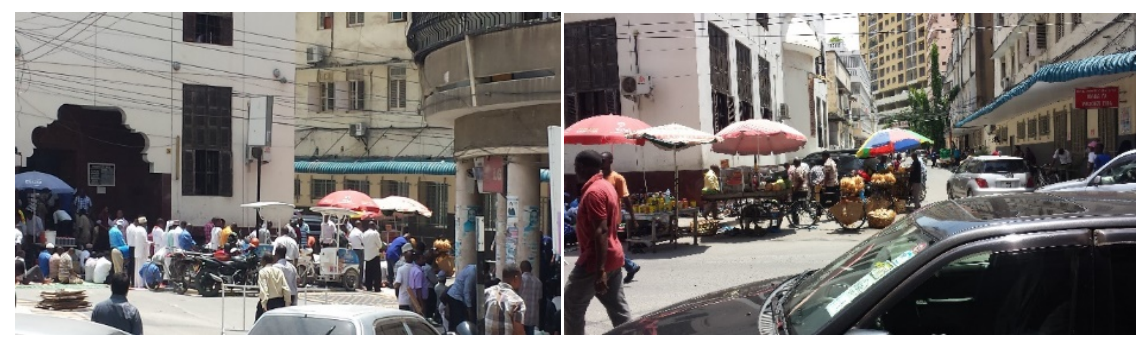

Source: Field photos.

Figure 5. The street and its activities closed as the Friday Muslim worship takes place. Temporary trading points for selling refreshments are set in place to serve the crowd of worshipers.
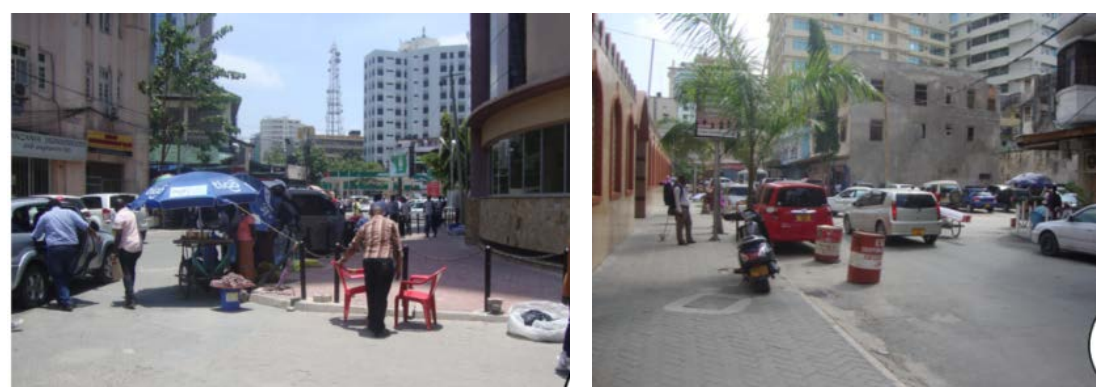

Source: Field photos.

Figure 6. Left. Diverted walkway at one of corporate buildings by providing walking barriers. Right: improved Walkway surface and provision of plant material by the adjacent building owner or tenant. 


\section{Architectural Elements and buildings}

Mixed-use buildings seem to dominate most of the streets in the city centre of Dar es Salaam particularly in the case study streets. Streets are highly articulated and strengthened as the building height increases. This situation is experienced in Kariakoo where the building heights range from three to ten plus floors and much more building height in the city centre. Most of the buildings are occupied with commercial activities at the ground floor or sometimes the basement to the first floor while the upper floors are designated for residential or office purposes. Having such activities in numerous buildings may attract high population. Some buildings with arcades may facilitate walking although some of walkways are occupied by petty trading. Most buildings in Kariakoo have related architectural elements such as grilled balconies, window series, surface textures and colours, which create certain visual continuity and uniformity. The buildings with first floors as commercial spaces mostly use balconies for displays of goods and so providing greater exposure to customers to get attracted. Given to the concentration of petty trading activities at the ground level, the architectural image at that level have turned into "user influenced visual pattern" (see Figures 7-12).
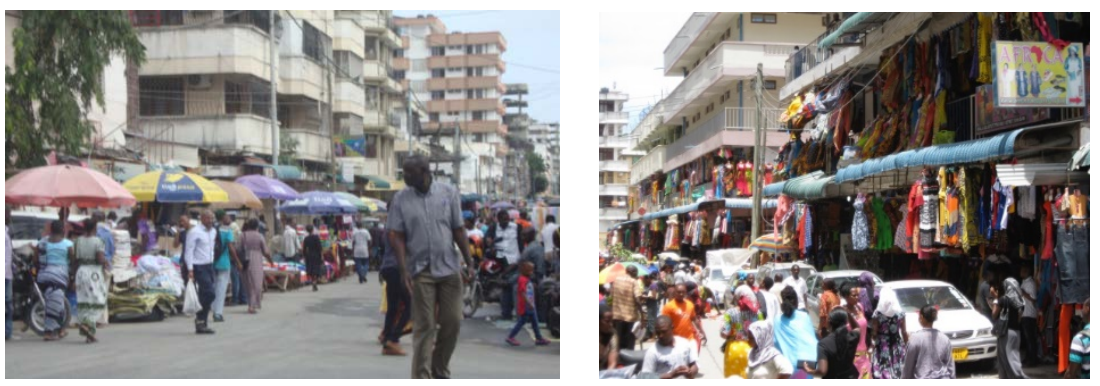

Source: Field photos.

Figure 7. Left: Nyamwezi street in Kariakoo: Similar architectural elements on buildings. Both sides of the street are fully occupied by petty trading activities. The walking and trading activities, displayed goods, makeshift structures, car parking, biking and driving play greater contribution to the architecture of the street. Walking take part in the road where the movement of cars are highly discouraged. Right: Commercial activities occupy the ground and first floor. Trading activities, car parking and other social activities are taking place concurrently such that they dominate the architectural image of the street.
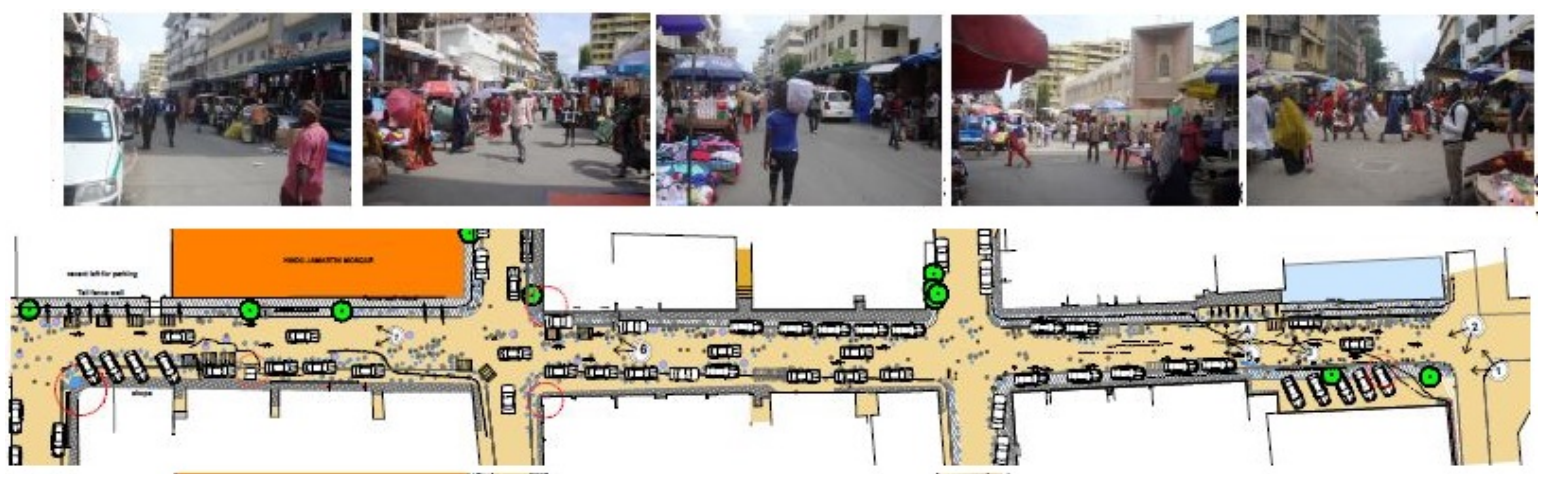

Source: Authors' construction.

Figure 8. Nyamwezi Street layout and the images in Kariakoo, Dar es Salaam. Social activities, trading activities, walking, car parking and displayed goods form essential part of street architecture. 


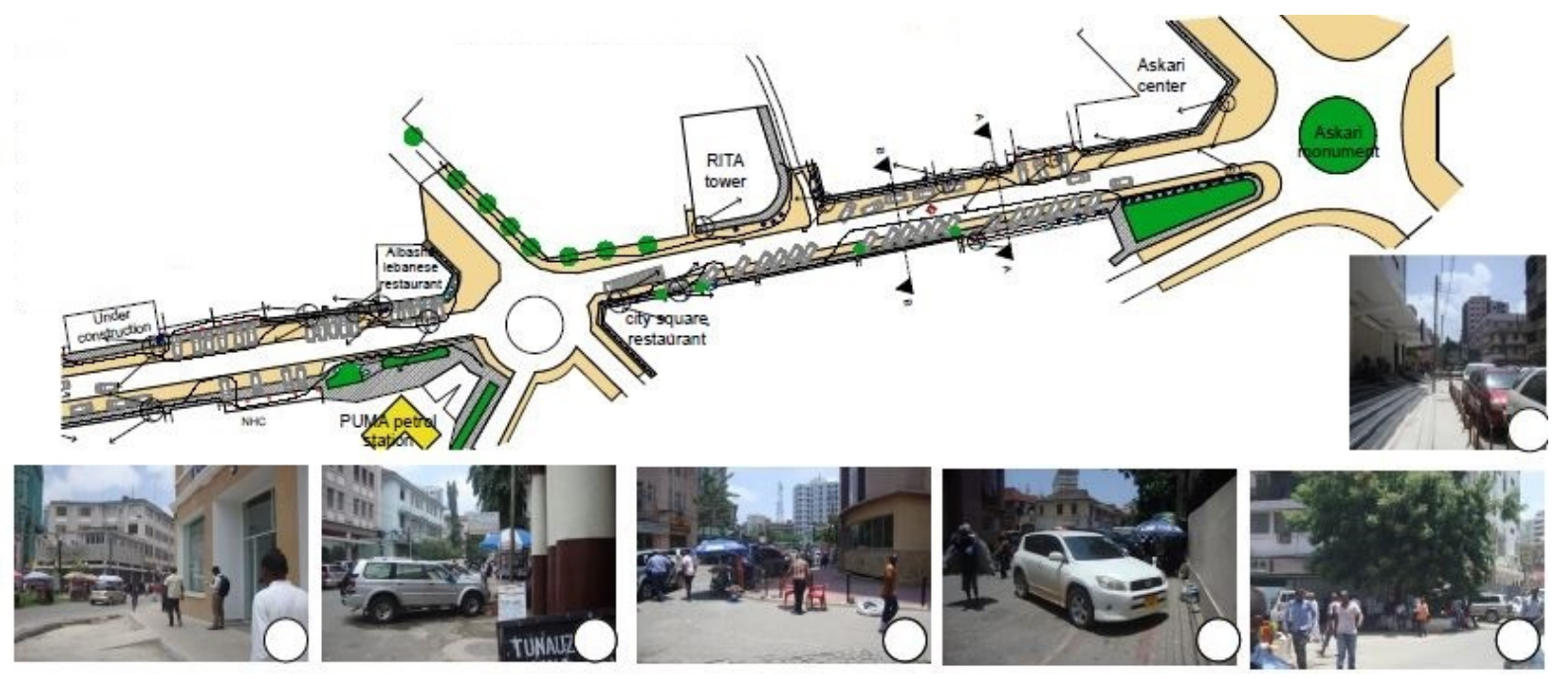

Source: Authors' construction and field photos.

Figure 9. Indira Gandhi Street layout and the images in Dar es Salaam city centre.

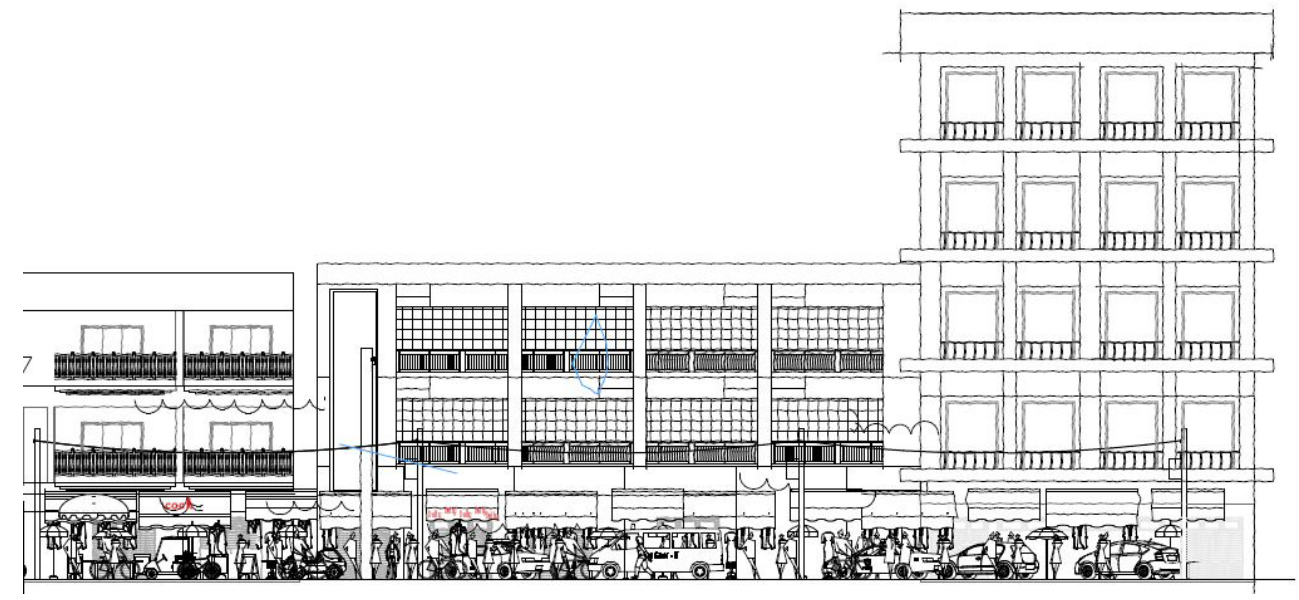

Source: Authors' construction.

Figure 10. The predetermined architectural image of the designer is evident from second floor above. The image on the ground and the first floor level adopt the dynamics of walking and socio-economic activities of the walkers, traders and the property owners.
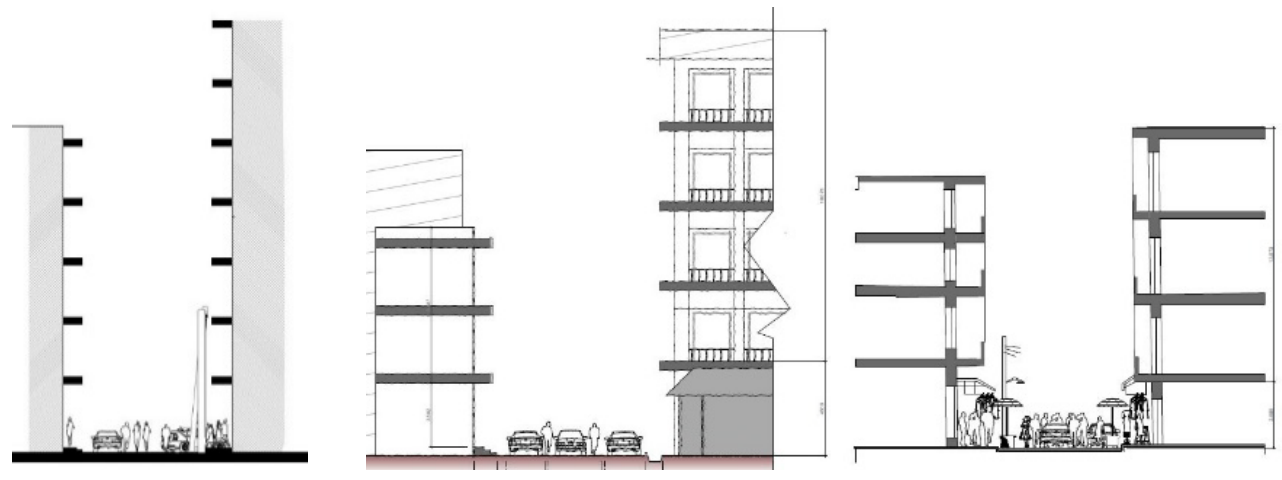

Source: Authors' construction.

Figure 11. The street enclosures from the highly concentrated space with walking and socio-economic activities to less concentrated where separation of activities can be made. 
Where less concentration of walking and socio-economic activities is experienced, more of architectural image of the designer is maintained and less effect of dynamics of walking and socio-economic activities.

\section{Street Furniture and Vegetation}

Certain streets with streetlights; ramps, stairs, benches, walkway safety rails, furniture and vegetation are noticed to be provided and maintained by individuals owners or investors on the adjoining buildings. At Jamartin mosque along Indira Gandhi Street there is provision of streetlights and planted which enhance scenery and facilitate walking (see Figure 13). However, there is hardly planted vegetation in Kariakoo area. Generally, street furniture such as street lights, street benches, ramps, safety rails, statues, water fountains, vegetation and others are hardly provided in most cases.

\subsection{The Street Users' Perspective}

This part presents the walkers' and the petty traders' perspective on the effect of street to their activities. It records the users' opinions on how and why environmental,

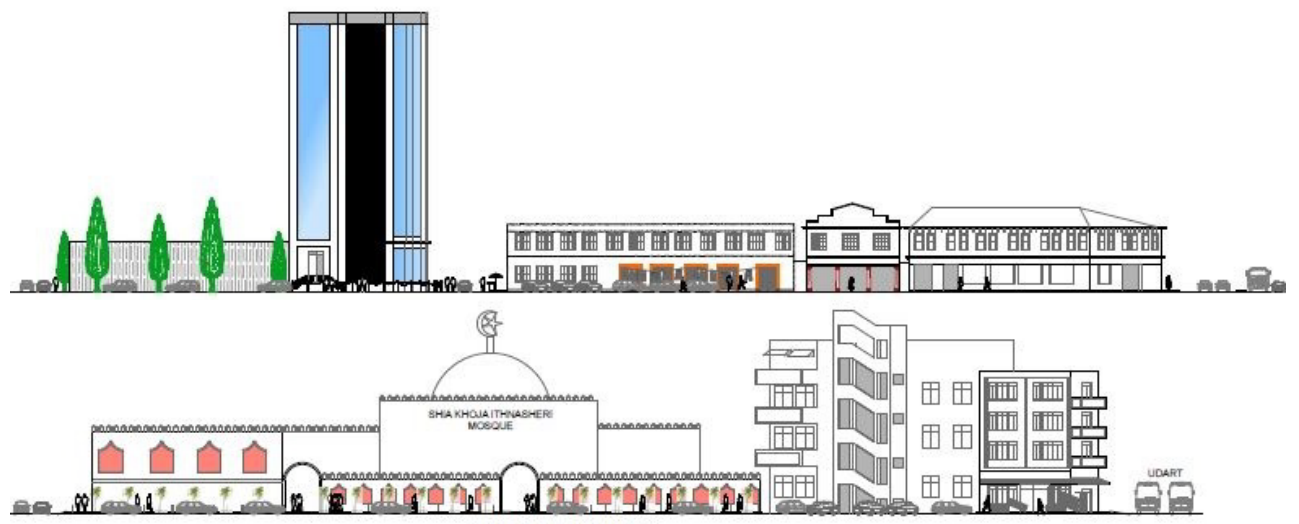

Source: Authors' construction.

Figure 12. Part of street elevations along Indira Ganthi Street in Dar es Salaam. The continuous change of architectural elements and height of buildings create certain taste to walkers. In less concentration of walking, parking and trading activities, the elements on the series of buildings along the street create the architecture of the street.
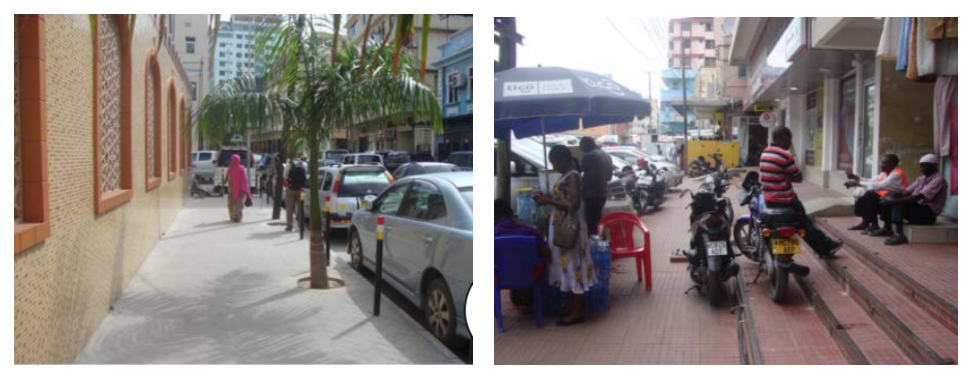

Source: Field photos.

Figure 13. Left: Vegetation along the Mosque giving taste to street landscape and articulating walking space. Right: Steps on building frontage used as part of street furniture in Kariakoo area. 
social, economic, spatial and architectural aspects influence their feeling and perception of street spaces. These contributions are used to develop the understanding in design discipline which is built based on specific users' perspective.

Walking condition (from the walkers perspective in Dar es Salaam)

A total amount of interviewed walkers is 120 . With regards to Figure 14, looking at walking behaviour, many interviewed walkers prefer to walk for shorter distances ( 1 to 3 kilometres) and may use public transport for longer distances. Only few respondents seem to prefer walking for both shorter and longer distances. Saving transport cost is one of important motive for tolerating longer walking distance in this case. It is noted that before people get to the city centre, they usually pre-plan on how they would make movements within the city centre. It is revealed that more than half of interviewed walkers prefer to walk than using public transport when they move in the city centre. One third of respondents indicated that they strictly walk when they are within the city centre and very few claim to use public transport whenever possible when they move in city centre. Considering that strategic locations of public transport stations may facilitate walking convenience, more than two third of interviewed walker are satisfied with locations of bus stop in the city centre. They also indicated that other public transport they use apart from daladala are motorbike, two third; bajaji, almost one third; and taxi, about one tenth. More than half of those who go to city centre using their private cars expressed the difficulty faced to secure parking space near their destination. The feeling of safety is one of important factor when one walks in order to enhance walking convenience and comfort. In this case, most walkers interviewed felt the lack of safety because they mostly walk on car carriageway due to obstructions created by petty traders, parked cars, landlord security restrictions and others on walkways.

\section{Walking Condition in Dar es Salaam City Centre}

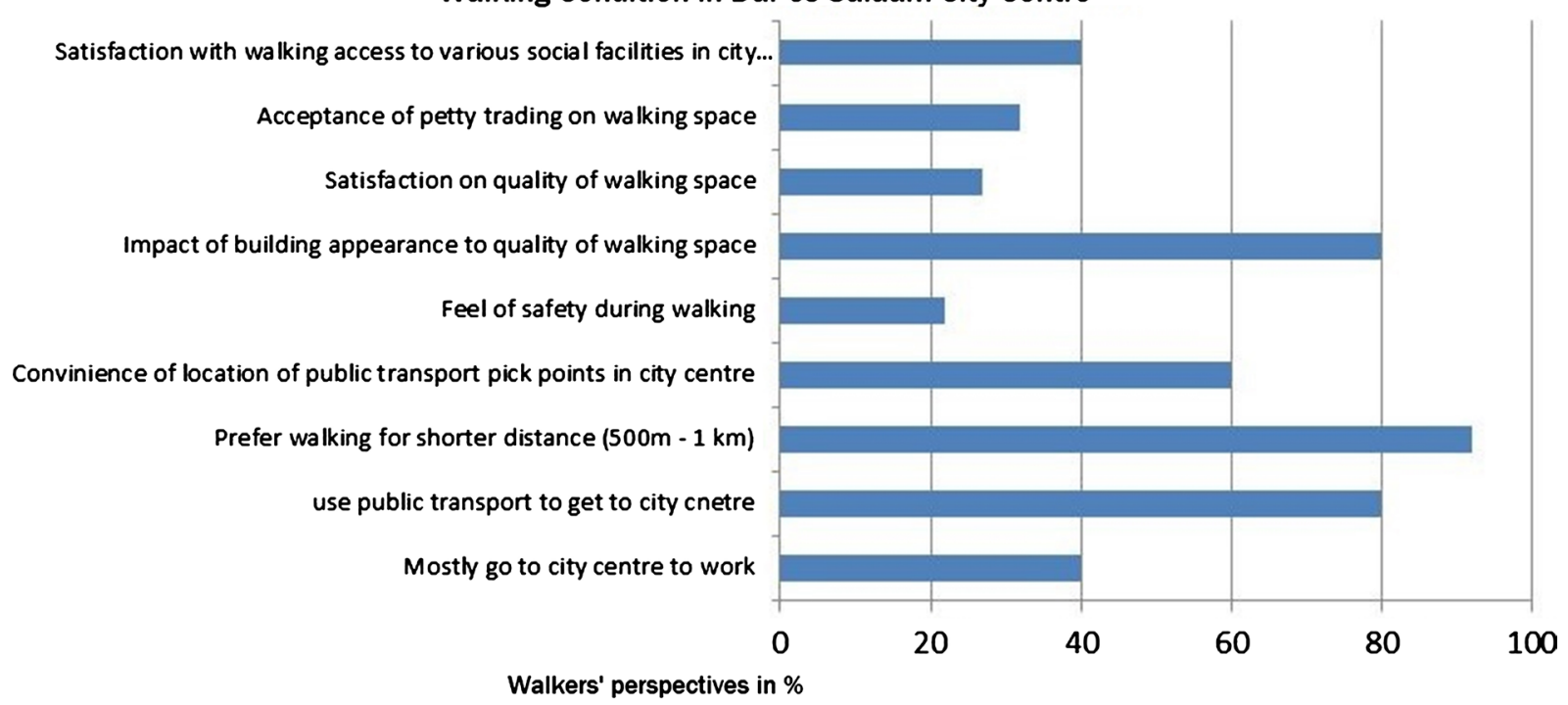

Source: Authors' construction.

Figure 14. Walkers' perspective in issues related with walking, activities and spatial condition in walking space. 
On the architectural aspects and visual expression in the walking space, the appearance of buildings are considered by more than two third of interviewed walkers to make the walking space attractive and enhance the walking experience. It is noted that the building elements like windows, balconies, canopies, stairs, glass curtains, series of attractive building on streets and the like are adding attractive impression to the street. Further, on other components apart from buildings which attracted the walkers include more than half of walkers being impressed by various commercial billboard display, one fifth being impressed by mixing with other walking people in the street, about one tenth being impressed by the moving cars along the street and one fifth being impressed by the petty traders and the display of their goods along the streets.

Regarding the quality of walking facilities, almost all walkers are not satisfied with the quality of walking environment due to obstructions including petty traders, parked cars, inconsistent quality of walking paving, less capacity of walkway to accommodate walkers and the like. On the aspect of activities taking place on walking space, almost nine tenth of walkers felt that the activities on street such as petty trading are not legal, interfere with their walking and reduce the quality of walking space. However, one fifth of walkers interviewed had the opinion that the informal activities along the walking route contribute to make the walking environment livelier. On the aspect of the activities which impress the walkers, one third indicated that engaging with the petty trading activities, looking at the goods on market and buying are part of interesting experience to them. More than two third are impressed with seeing other people moving, standing, sitting, charting and the like. The destinations which are preferred by walkers when they visit the city centre are mainly three, including: shopping malls; cafés; and beaches with the preference rate of one fifth, three quarter and about one tenth respectively.

Two third of interviewed walkers opinions show that the location of important facilities such as shops, shopping malls, markets, bus stops, open spaces, banks, government offices, health centres and other are not easily accessed through walking since the strategic location of public transport transit points are not located within the convenient walking distances.

Trading condition in walking space (from the petty traders perspective in Dar es Salaam)

A total number of interviewed petty traders is 60 . As noted in Figure 15, petty traders are choosing their location based on suitability of making their business. Therefore, the walking spaces mostly seem to be the target since they are clear, open to public and accessible with walkers. In this case, they choose their location strategically depending on space availability and access to customers which result to varying concentration of petty trading activities in different streets in the city centre. It is found that two third of traders interviewed acquired their trading space through connection with friends and acquaintances. Almost three quarter of interviewed petty traders preferred the location of trading space with considerable 
concentration of working community to supplement the walking customers. Nine tenth of petty traders interviewed consider their choice of trading space suitable for display of their goods and access to customers.

Only half of interviewed petty traders considered the physical quality as one of the factor for choice of trading space. The aspect which held greater importance in choice of trading space is the access to customers and hence guaranteeing earning of an income (see Figure 16). More than three quarter of interviewed petty traders acknowledge that walkers are complaining about their interference with their walking comfort. However, the petty traders understand their interference with the walking but they claim to engage in that activity as the only way to make an income and meet their basic need for living in the city. In that respect, about two third of interviewed petty traders indicated that the need to make income is prioritized than interfering with the walking activity. The petty traders seem to be content with the income they make at their location such that more than two third of interviewed petty traders indicated that they are not ready to move if the city authority provide the offer of legal and appropriate alternative location. This appears to refer to past experience where the city authority

\section{Petty Traders on walkway in Dar es Salaam City}

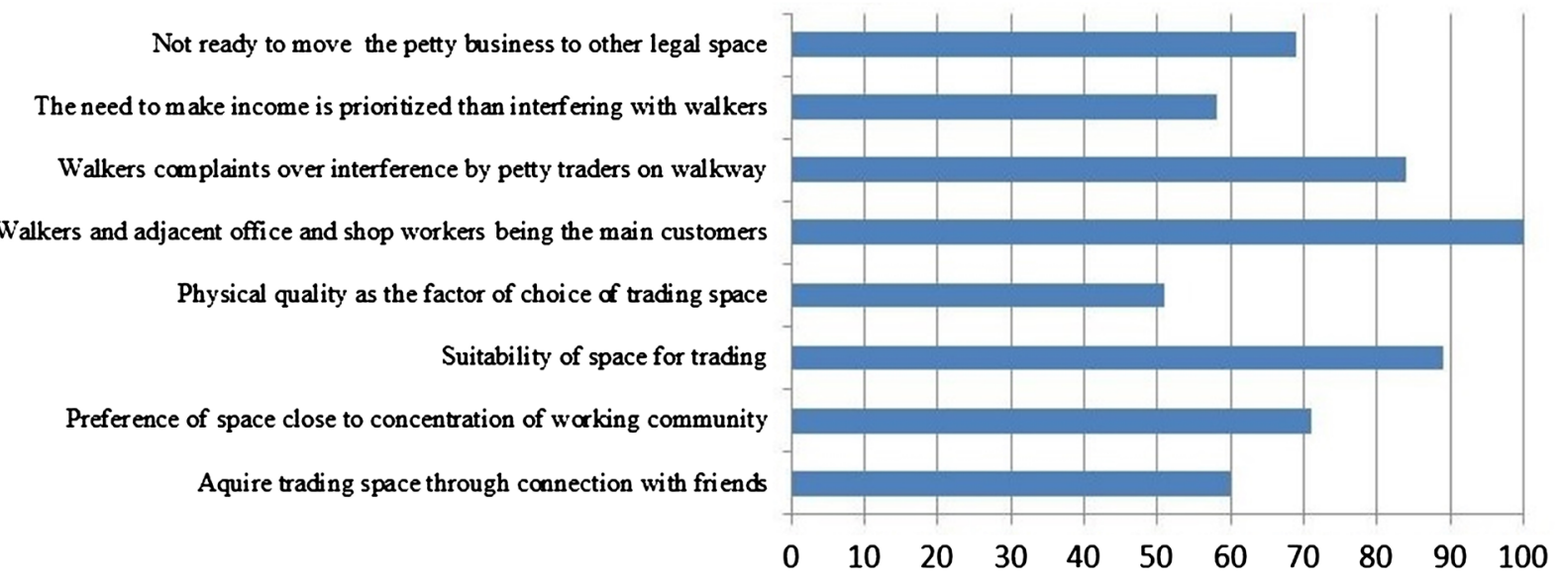

Petty Traders' Perspective in \%

Source: Authors' construction.

Figure 15. Petty traders reactions to issues related to space use, interaction with walkers and the street space condition.

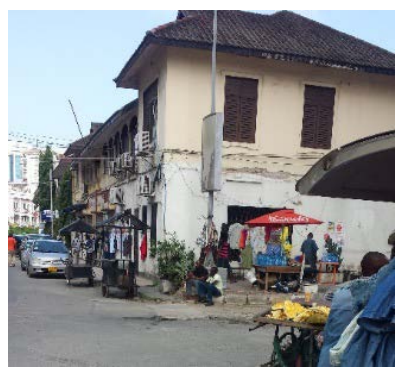

Source: Field photos.

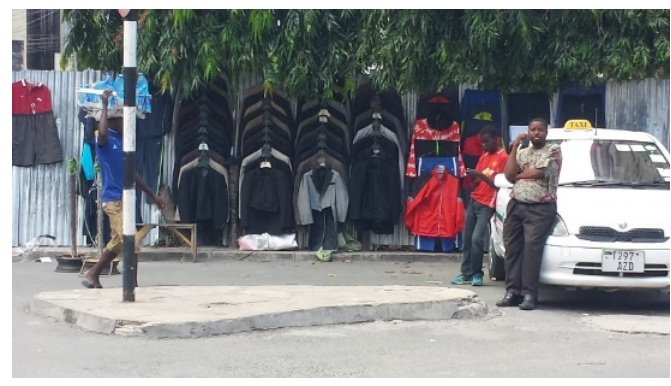

Figure 16. Trading location depends on exposure and access to customers where walking people are the main target. 
evict petty traders from their street informal locations to remote and isolated areas where they end up losing customers, business and income. Generally, the study indicates a connection of walking space, the petty trading, the city context and the walking activity that form a shared spatial domain of urbanity. This unity of activities and the actors in the street may not be ignored by the design of urban street.

\subsection{City Design Approach}

The interview with planning officials in Dar es Salaam city indicate that the design approach adopted emphasise the holistic provision of basic facilities and infrastructure sufficient to ensure efficient operation of the street functions and the city as a whole. Such holistic components include commercial, residential, industrial, institutional and mixed use zones. Such zones are connected with various basic services including road networks which compose street at various capacities. Streets appear as the result of road provision and the series of building along the road and not specifically preconceived street design which consider the user socio-economic context. Walking, as the major mobility mode at street level, is not conceived sufficiently as the influential design tools to street spatial organization and form. It is also noted that the programmes of provision and improvement of road networks in cities hardly consider walking as the means of transport and opportunity for the users to experience the city space. The evidence of less integration of walking as integral part of street design is a rare provision of physical and visual walking features.

Unauthorised petty trading in city is one of common practices on streets. In professional perspective, it is "not acceptable" as they miss professional design and planning values. The persistence of petty trading interference with the planned land use such as formal street business, vehicular movement, pedestrian passage, car parking, street image and others has created the norms, tradition and common trends dominating the everyday practices and physical configuration of the streets. In this respect, petty trading practices are mostly part of city streets where street walking and other activities are shaped. The petty trading practices address the social groups which are less accommodated by the design regime forcing their way to search for survival within the socio-economic and cultural reality of city. This has affected the organization, function and the image of city streets and the walking condition. These informal practices and city realities have to be taken as important input in reconceptualising the design approach to achieve relevant urban street and city space commensurate to local context.

\section{Discussion}

Apart from the street professional design represented by the conventional design principles, some unconventional design features are contributed by the building owners, tenants and the informal actors. This creates a spectrum of several ac- 
tors in effecting the street physical configuration with less defined method of coordination or unified interest. The contradiction of petty traders interfering with walking efficiency while the walkers are reliable customers to them is the complex relationship beyond professional conception but afford to enhance social order in the confinement of the street as noted by some analysts (Shortell, 2016; Ramsden, 2014; Wallmann, Bucksch, \& Froboese, 2011; Wineman, Kabo, \& Davis, 2009; Moughtin, 2003; Ben-Joseph, 1995). This system of street evolution tends to fill the gap of deficiency in professional approach and culture of control the design and maintenance of street architecture.

The intervention to shape the street to meet certain requirements involves the interplay of individual and collective requirements of the street actors which justify the contestation of different groups to exploit the space value (Hamilton-Baillie, 2008; Methorst, Gerlach, Boenke, \& Leven, 2007; Harvey, 2007; Moughtin, 2003). The competition of outdoor trading and its quest to attract customers pose challenge to walking convenience, comfort and safety. The intensity of commercial activities on street tend to promote walking, display and sale of goods and services both indoor and outdoor which improve liveability and vibrancy which overshadow some other quality weaknesses.

Formal provision of walking and parking and outdoor furniture are not consistent which allow the street users to informally improvise the combination of street character as enclosure which play the role of attracting walkers despite deficiency on quality of walking environment. The higher response of walkers as part of customers to engage in street trading indicates important connection of the actors and its impact to the street vibrancy. Such phenomenon is supported by the need to address the common attributes in order to facilitate interaction among people and groups in street space (Shortell, 2016; Ramsden, 2014; Wallmann, Bucksch, \& Froboese, 2011; Wineman, Kabo, \& Davis, 2009; Moughtin, 2003; Ben-Joseph, 1995). In streets where such connection is high, the concentration of outdoor petty trading is greater such that the display of goods and makeshift structure dominate the architecture of the street. The triggered commercial dynamics on street space dominate the physical configuration and architecture of the street. Such phenomenon is mostly ignored by the architectural perspective which conceives the notion of control of uninterrupted architectural image.

Quality and safety of space for walking being rated low by the walkers are yet rendered less important since concentration of space use is high which reflect the users' socio-cultural preferences as noted by Koohsari et al. (2013). Contrary to street professional design which provides separation of walking and driving to enhance safety, quality and comfort, the highly occupied street by the formal and informal activities transform the street to shared space for walking, cycling, biking and driving. As note by Hamilton-Baillie (2008) the reduced speed and elimination of walking barriers increase the communication among the drivers and walkers which improve safety and comfort to walkers. In case of Nyamwezi 
Street, the concentration of trading activities is one of important factors encouraging massive walkers which tend to make the comfort aspect to take the secondary priority. The demand for trading activities have expanded to the extent of shaping the architecture of the street which depict the display of goods, temporary structures and the interaction of traders, walkers, drivers and riders. This reflect to everyday aspiration achieved by the street contributing to its vibrancy (Kärrholm, Johansson, Lindelöw, \& Ferreira, 2014; Reyer, Fina, Siedentop, \& Schlicht, 2014; Blaga, 2013). The combination of socio-economic activities, cultural expression and physical outlook complement the architecture of the street. The evidence shows that the pre-designed architectural image of the street can be influenced by the formal, informal and cultural features as part of street dynamics. These aspects have to be known and accommodated in professional design discourse for urban space and street to reconcile appropriately with local, traditional and cultural aspects of street architecture.

\section{Conclusion}

Professional design of street concentrates on generic values on efficiency, safety, comfort, accessibility, architectural expression and the like. It has been revealed that such values have to be complemented by the local socio-economic and cultural values. While professional architecture tends to concentrate on physical expression of the built environment to human, the socio-economical and cultural forces in cities of least developed economies contribute to shaping the street space. Utility and adequacy to meet everyday functional requirements that accommodate the condition and low income status of the people dominate the values which influence the architecture and usability of the street. Walking and socio-economic activities in street are closely associated in determining the organization and physical configuration of the street. The understanding of socio-economic and cultural factors of the population in cities of least developed countries is important in the design of urban space, street and the city at large. While the formal professional aspects are important, the room for acceptable and inevitable informal elements has to be allowed in order to ensure relevance to the architecture of the street and the city at large.

\section{Conflicts of Interest}

The authors declare no conflicts of interest regarding the publication of this paper.

\section{References}

Alfonzo, M. (2005). To Walk or Not to Walk? The Hierarchy of Walking Needs. Environment and Behavior, 37, 808-836. https://doi.org/10.1177/0013916504274016

Alfonzo, M., Boarnet, M. G., Day, K., Mcmillan, T., \& Anderson, C. L. (2008). The Relationship of Neighbourhood Built Environment Features and Adult Parents' Walking. Journal of Urban Design, 31, 29-51. https://doi.org/10.1080/13574800701803456 
Ben-Joseph, E. (1995). Changing the Residential Street Scene: Adapting the shared street (Woonerf) Concept to the Suburban Environment. Journal of the American Planning Association, 61, 504-515. https://doi.org/10.1080/01944369508975661

Blaga, O. E. (2013). Pedestrian Zones as Important Urban Strategies in Developing the Community-Case Study: Alba Iulia Borough Park. Transylvanian Review of Administrative Sciences, 5-22.

Bourbia, F., \& Fouzia, B. (2010). Impact of Street Design on Urban Microclimate for Semi Arid Climate (Constantine). Renewable Energy, 35, 343-347.

Cubukcu, E. (2013). Walking for Sustainable Living. Procedia-Social and Behavioral Sciences, $85,33-42$.

Hamilton-Baillie, B. (2008). Shared Space: Reconciling People, Places and Traffic. Built Environment, 34, 161-181. https://doi.org/10.2148/benv.34.2.161

Harvey, D. (2007). Contested Cities: Social Process and Spatial Form. In R. T. LeGates, \& F. Stout (Eds.), The City Reader (4th ed., pp. 225-232). London: Routledge.

Jacobs, J. (1961). The Uses of Sidewalks: Safety. In R. LeGates, \& F. Stout (Eds.), The City Reader (4th ed., pp. 98-102). New York: Routledge.

Kärrholm, M., Johansson, M., Lindelöw, D., \& Ferreira, I. A. (2014). Interseriality and Different Sorts of Walking: Suggestions Suggestions for a Relational Approach to Urban Walking. Mobilities, 12, 20-35. https://doi.org/10.1080/17450101.2014.969596

Koohsari, M. J., Karakiewicz, J. A., \& Kaczynski, A. T. (2013). Public Open Space and Walking: The Role of Proximity, Perceptual Qualities of the Surrounding Built Environment, and Street Configuration. Environment and Behavior, 45, 706-736. https://doi.org/10.1177/0013916512440876

Levy, R. M. (2006). The Visualisation of the Street Computer Modelling and Urban Design. In N. R. Fyfe (Ed.), Images of the Street: Planning, Identity and Control in Public Space (pp. 58-70). London: Taylor \& Francis.

Makki, S., Surat, M., Che-Ani, A., Farkisch, H., \& Mokhtarian, H. (2012). The Importance of Design Characteristics in Walking from Student's Perspective: A Case Study in Universiti Kebangsaan Malaysia. Journal of Building Performance, 3, 42-49.

Mehta, V. (2008). Walkable Streets: Pedestrian Behavior, Perceptions and Attitudes. Journal of Urbanism: International Research on Placemaking and Urban, 1, 217-245. https://doi.org/10.1080/17549170802529480

Methorst, R., Gerlach, J., Boenke, D., \& Leven, J. (2007). Shared Space: Safe or Dangerous? A contribution to objectification of a popular design. In WALK21 Conference. Toronto: WALK 21.

Moughtin, C. (2003). Urban Design: Street and Square (3rd ed.). Oxford: Architecture Press.

National Association of City Transportation Officials (2013). Urban Street Design Guide. Washington DC: Island Press.

Planning Institute Australia (2003). Planning Healthy Communities: A PIA Discussion Paper on Public Health and Wellbeing: A Basis for Developing a Draft Policy Statement on Planning for Health. Victoria: Planning Institute Australia.

Ramsden, H. (2014). A Walk around the Block: Creating Spaces for Everyday Encounters. In T. Shortell, \& E. Brown (Eds.), Walking in the European City: Quotidian Mobility and Urban Ethnography (pp. 225-244). Burlington: Ashgate.

Ramsden, H. (2016). A Walk around the Block: creating spaces for everyday encounters. In T. Shortell, \& E. Brown (Eds.), Walking in the European City: Quotidian Mobility and Urban Ethnography (pp. 225-244). New York: Routledge. 
Reyer, M., Fina, S., Siedentop, S., \& Schlicht, W. (2014). Walkability Is Only Part of the Story: Walking for Transportation in Stuttgart, Germany. International Journal of Environmental Research and Public Health, 11, 5849-5865.

https://doi.org/10.3390/ijerph110605849

Shishegar, N. (2013). Street Design and Urban Microclimate: Analyzing the Effects of Street Geometry and Orientation on Airflow and Solar Access in Urban Canyons. Journal of Clean Energy Technologies, 1, 52-56. https://doi.org/10.7763/JOCET.2013.V1.13

Shortell, T. (2016). Walking as Urban Practice and Research Method. In E. Brown, \& T. Shortell (Eds.), Walking in Cities: Quotidian Mobility as Urban Theory, Method and Practioce (pp. 1-16). Philadelphia, PA: Temple University Press.

Temelová, J., \& Novák, J. (2011). Daily Street Life in the Inner City of Prague under Transformation: The Visual Experience of Socio-Spatial Differentiation and Temporal Rhythms. Visual Studies, 26, 213-228. https://doi.org/10.1080/1472586X.2011.610944

Transport for London (2004). Making London a Walkable City-The Walking Plan for London. London: Mayor of London.

Vestergaard, M. Q., Olesen, M., \& Helmer, P. F. (2014). The Act of Walking: Exemplifying Danish Pedestrian Culture. In T. Shortell, \& E. Brown (Eds.), Walking in the European City: Quotidian Mobility and Urban Ethnography (pp. 41-56). Burlington: Ashgate.

Wallmann, B., Bucksch, J., \& Froboese, I. (2011). The Association between Physical Activity and Perceived Environment in German Adults. European Journal of Public Health, 22, 502-508. https://doi.org/10.1093/eurpub/ckr069

WHO (2011). Make Walking Safe: A Brief Overview of Pedestrian Safety around the World.

http://who.int/violence_injury_prevention/publications/road_traffic/make_walking_sa fe.pdf

Wineman, J. D., Kabo, F. W., \& Davis, G. F. (2009). Spatial and Social Networks in Organizational Innovation. Environment and Behavior, 41, 427-442. https://doi.org/10.1177/0013916508314854

Woolley, H., Rose, S., Carmona, M., \& Freedman, J. (2003). The Value of Public Space: How High Quality Parks and Public Spaces Create Economic, Social and Environmental Value. London: CABE Space.

Wundelich, F. M. (2008). Walking and Rhythmicity: Sensing Urban Space. Journal of Urban Design, 13, 125-139. https://doi.org/10.1080/13574800701803472 